\title{
Recruitment of the Serratus Anterior as an Accessory Muscle of Ventilation during Graded Exercise
}

\author{
Daniel T. CANNON ${ }^{1}$, Sara L. GROUT ${ }^{1}$, Courtney A. MAY ${ }^{1}$, Stephanie D. STROM ${ }^{1}$, \\ Kathryn G. WYCKOFF ${ }^{1}$, Daniel J. CIPRIANI ${ }^{1}$, and Michael J. BUONO ${ }^{1,2}$ \\ ${ }^{1}$ School of Exercise and Nutritional Sciences and ${ }^{2}$ Biology Department, San Diego State University, San Diego, CA 92182-7251, USA
}

\begin{abstract}
The role of the serratus anterior (SA) as an accessory muscle of ventilation and its physiologic significance under exercising conditions remains unclear. Recent investigations have utilized the measurement of $\mathrm{SA}$ as an analog for respiratory muscle oxygenation. The purpose of this investigation was to examine the action of the serratus anterior via surface electromyography (EMG) and near infrared spectroscopy (NIRS) during exercise while controlling for muscular effort not related to ventilation. Nine healthy volunteers (age $=24.4 \pm 0.5$ years, $\dot{\mathrm{V}} \mathrm{O}_{2 \max }=3.416 \pm 0.35 / \mathrm{min}^{-1} ; \dot{\mathrm{V}}_{\text {Epeak }}=127.5 \pm 13.1 / \mathrm{min}^{-1}$; $\mathrm{TV}_{\text {peak }}=2.844 \pm 0.226$ I) completed a graded exercise test to volitional exhaustion on a cycle ergometer. The subjects' arms were folded and relaxed at the abdomen to minimize muscular effort resulting from scapular stabilization during pushing/for-
\end{abstract}

ward flexion of the arms associated with cycle ergometry. $\dot{\mathrm{V}}_{2}$ and $\dot{V}_{E}$ were monitored breath-by-breath throughout exercise. EMG was recorded over the right $S A$, and a near infrared probe was placed over the left $S A$. No significant differences were observed throughout the graded exercise test for tissue oxygenation $\left(\mathrm{StO}_{2}\right)\left(n=6, \mathrm{~F}[1.532,7.661]=0.895, P>0.05, \eta^{2}=0.15\right)$ or EMG $\left(n=9, \mathrm{~F}[1.594,12.75]=3.067, P>0.05, \eta^{2}=0.27\right)$. Although the recruitment of the SA has been postulated to aid in ventilation in various postures and disease states, it is concluded that it shows little muscular effort in healthy subjects during upright cycling. Additional research is needed to conclude the pertinence of utilizing $\mathrm{StO}_{2}$ of the $\mathrm{SA}$ as an analog for respiratory muscle oxygenation.

Key words: electromyography (EMG), near infrared spectroscopy (NIRS), cycling, ergometer, oxygenation.

The serratus anterior (SA) muscle has often been described as an accessory muscle during ventilation, though considerable debate continues as to its specific role in relation to various postures and the subject's health or diseased state [1-6]. The SA originates from the first through the eighth or ninth ribs, inserting at the anterior surface of the vertebral border of the scapula [7]. In addition to upward rotation, protraction, and stabilization of the scapula, the SA has also been theorized to elevate the rib cage during inspiration and therefore act as an accessory muscle of ventilation $[4-6,8]$.

Throughout the mid-20th century, investigators challenged the notion that the SA was involved in ventilation $[1,9]$. Disease states and postures have also been shown to influence muscle tone and phasic activity during breathing, though researchers were unable to consistently measure activity in the SA during forced breathing, with no activity present during quiet ventilation in healthy subjects [2]. Based on these findings, texts published during the 1970s and 1980s concluded that the SA takes no part or, at best, is unlikely to be recruited for ventilation [3, $10]$.
Investigations employing more advanced techniques successfully identified activity in the SA during ventilation, though with little consistency. Electromyography has been employed to identify phasic activity of the SA in both inspiration and eccentrically during expiration $[4,5]$. It was concluded that the SA must be considered an accessory muscle of ventilation, especially in certain postures and diseases, and that the identification of an inspiratory or expiratory role alone may be insufficient to describe its complex action [4-6]. Although these most recent investigations provide strong evidence for the phasic respiratory action of the SA, it is still unclear how the muscle is activated for labored breathing during exercise, or whether the muscle makes a physiologically significant contribution to ventilation.

Recent publications have examined the oxygenation of the SA as a measure of accessory respiratory muscle perfusion with near infrared spectroscopy (NIRS) during cycle ergometry. NIRS is a noninvasive technique used to assess tissue oxygenation $\left(\mathrm{StO}_{2}\right)$ derived from light absorption changes in small arterioles, capillaries, and venuoles [11]. Researchers have observed the respiratory

Received on Feb 22, 2007; accepted on Apr 3, 2007; released online on Apr 6, 2007; doi:10.2170/physiolsci.RP001807 Correspondence should be addressed to: Daniel T. Cannon, School of Exercise and Nutritional Sciences, San Diego State University, 5500 Campanile Drive, San Diego, CA 92182-7251, USA. Tel: +1-619-885-5120, Fax: +1-619-594-6553, E-mail:

dcannon@rohan.sdsu.edu 


\section{D.T. CANNON et al.}

deoxygenation point (as assessed with NIRS) with strong correlation to the respiratory compensation point (RCP), and/or the ventilatory threshold $\left(\mathrm{V}_{\mathrm{T}}\right)$, in disease and health [12-15]. Investigators have reported a strong correlation of the muscle deoxygenation point measured at the SA, and the $\mathrm{V}_{\mathrm{T}}$ in healthy children and adults [13-15]. This fall in tissue oxygenation has been postulated as an indication of the oxygenation state of the diaphragm, and this finding may provide insight into the mechanism of exertional dyspnea in cardiac patients $[12,16,17]$.

As a result of the subjects grasping the handlebars of the cycle ergometer, muscular work to stabilize the scapula during cycling exercise [12-17] may have confounded the results obtained via NIRS. Furthermore, the fall in $\mathrm{StO}_{2}$ of exercising and nonexercising skeletal muscle is well correlated with $\mathrm{V}_{\mathrm{T}}$ or the RCP and is associated with hyperventilation [18-20]. These findings suggest the possibility that changes in $\mathrm{StO}_{2}$ in the $\mathrm{SA}$ may be a result of perfusion changes from a redistribution of blood flow. The assertion that SA deoxygenation is due to muscular effort related to ventilation has yet to be determined, because the specific action is not yet fully understood, especially during exercise and the posture of cycling. Thus the purpose of this investigation was to examine the action of the SA via surface electromyography (EMG) and NIRS during maximally graded cycling exercise, while controlling for muscular action-related scapular stabilization.

\section{METHODS}

Subjects. Nine healthy university students volunteered to participate. Subject characteristics are presented in Table 1. Participants were screened for cardiovascular disease with the Physical Activity Readiness Questionnaire (PAR-Q). The study protocol was approved by the San Diego State University Institutional Review Board, and written informed consent was obtained from all volunteers be- fore participating. All procedures complied with the Declaration of Helsinki.

Experimental protocol. Subjects completed a maximally graded exercise test on an electromagnetically braked cycle ergometer (Excalibur Sport, Lode BV, Groningen, The Netherlands). The subjects' arms were relaxed and folded at the abdomen during the exercise test to reduce the muscle activity related to scapular stabilization. The exercise began at a power output of $50 \mathrm{~W}$ for a duration of $3 \mathrm{~min}$ and was then increased at a rate of $25 \mathrm{~W} \mathrm{~min}^{-1}$ until volitional exhaustion. Oxygen consumption $\left(\dot{\mathrm{VO}}_{2}\right)$ and $\mathrm{CO}_{2}$ production $\left.(\dot{\mathrm{V} C O})_{2}\right)$ were measured with a breath-bybreath metabolic measurement system employing a hotwire anemometer for the calculation of expired volume $\left(\dot{\mathrm{V}}_{\mathrm{E}}\right)$ (VMax Encore, VIASYS HealthCare, Yorba Linda, CA, USA). A true maximal effort was determined according to the following criteria: subject unable to maintain a pedal cadence of $60 \mathrm{rpm}$ and a RER $\geq 1$.1. All subjects received verbal encouragement until exhaustion. The ventilatory threshold $\left(\mathrm{V}_{\mathrm{T}}\right)$ was determined by multiple criteria, including a rapid increase in the ventilatory equivalent of oxygen $\left(\dot{\mathrm{V}}_{\mathrm{E}} / \dot{\mathrm{V}}_{2}\right)$ with no concomitant increase in the ventilatory equivalent of carbon dioxide $\left(\dot{\mathrm{V}}_{\mathrm{E}} / \dot{\mathrm{V} C O}_{2}\right)$, and the V-slope method [21]. $\dot{\mathrm{V}} \mathrm{O}_{2 \max } / \dot{\mathrm{V}}_{\text {Epeak }} /$ peak Tidal Volume $\left(\mathrm{TV}_{\text {peak }}\right)$ was determined from the highest $20 \mathrm{~s}$ average.

Electromyography. During the exercise test, EMG was used to evaluate the muscular work of the SA. Following skin preparation, bipolar $\mathrm{Ag} / \mathrm{AgCl}$ pregelled surface electrodes with an interelectrode distance of $2 \mathrm{~cm}$ were placed over the appropriate muscle belly. The conductive area of each electrode was $1 \mathrm{~cm}$ in diameter, and each bipolar electrode used a proximal differential amplifier. The right SA was monitored to minimize the ECG artifact [22]. The electrodes were placed horizontally at the level of the inferior edge of the scapula and medial to the latissimus dorsi [22]. Electrodes were placed on the latissimus dorsi to

Table 1. Subject characteristics.

\begin{tabular}{|c|c|c|c|c|c|c|c|}
\hline Subject & Age & $\begin{array}{l}\text { Height } \\
(\mathrm{cm})\end{array}$ & $\begin{array}{c}\text { Weight } \\
(\mathrm{kg})\end{array}$ & $\begin{array}{l}\dot{\mathrm{V}} \mathrm{O}_{2 \max } \\
\left(/ \mathrm{min}^{-1}\right)\end{array}$ & $\begin{array}{c}\dot{\mathrm{V}}_{\text {Epeak }} \\
\left(/ \mathrm{min}^{-1}\right)\end{array}$ & $\begin{array}{c}\mathrm{V}_{\mathrm{T}} \\
\left(\% \mathrm{VO}_{2 \max }\right)\end{array}$ & $\mathrm{TV}_{\text {peak }}$ \\
\hline 1 & 22 & 165 & 51.8 & 3.204 & 117.3 & 57.2 & 2.509 \\
\hline 2 & 25 & 170 & 75.0 & 3.525 & 123.3 & 49.4 & 2.477 \\
\hline 3 & 25 & 185 & 83.2 & 3.300 & 117.4 & 63.7 & 2.909 \\
\hline 4 & 23 & 185 & 79.5 & 5.330 & 184.2 & 58.8 & 4.261 \\
\hline 5 & 25 & 163 & 52.3 & 2.131 & 79.8 & 52.3 & 2.337 \\
\hline 6 & 26 & 178 & 71.4 & 4.070 & 152.4 & 46.9 & 2.823 \\
\hline 7 & 24 & 178 & 75.0 & 4.155 & 187.7 & 46.5 & 3.137 \\
\hline 8 & 26 & 168 & 56.8 & 2.621 & 96.7 & 62.6 & 2.810 \\
\hline 9 & 24 & 160 & 59.1 & 2.407 & 88.8 & 60.7 & 1.997 \\
\hline $\begin{array}{c}\text { Mean } \pm \\
\text { SE }\end{array}$ & $\begin{array}{c}24.4 \pm \\
0.5\end{array}$ & $\begin{array}{c}172.4 \pm \\
3.3\end{array}$ & $\begin{array}{c}67.1 \pm \\
4.3\end{array}$ & $\begin{array}{c}3.416 \pm \\
0.334\end{array}$ & $\begin{array}{c}127.5 \pm \\
13.1\end{array}$ & $\begin{array}{c}55.3 \pm \\
2.2\end{array}$ & $\begin{array}{c}2.844 \pm \\
0.226\end{array}$ \\
\hline
\end{tabular}


provide a check for cross talk. A common reference electrode was placed on the L1 spinous process. Manual muscle testing was performed on the SA to ensure adequate conduction and placement, including resisted forward flexion of the arms and push-up test [23]. Using the Noraxon Telemyo 2400 T transmitter (Noraxon USA, Scottsdale AZ, USA), the incoming signal was preamplified with a gain of 500 and included a channel filter of a firstorder high-pass filter at $20 \mathrm{~Hz}$ and an eighth-order Butterworth/Bessels low-pass antialias filter set at $500 \mathrm{~Hz}$. Each EMG channel had a common mode rejection ratio of greater than $100 \mathrm{~dB}$. The data were sampled and processed with a 12-bit A/D board at 1,500 Hz. Raw EMG signals were smoothed (RMS with a $50 \mathrm{~ms}$ moving window), and filtered for ECG noise (if necessary) prior to analysis. EMG RMS values were calculated for 2.5-s periods [6] for each minute during the exercise test using MyoResearch XP Master Edition software (Noraxon USA, Scottsdale, AZ, USA). The data were visually inspected and grouped and scaled across subjects according to the $\% \dot{\mathrm{V}}{ }_{2 \text { max }}$ at which the measurements were recorded.

Near infrared spectroscopy. Tissue oxygen saturation $\left(\mathrm{S}_{\mathrm{t}} \mathrm{O}_{2}\right)$ was monitored in the left SA using a tissue spec-
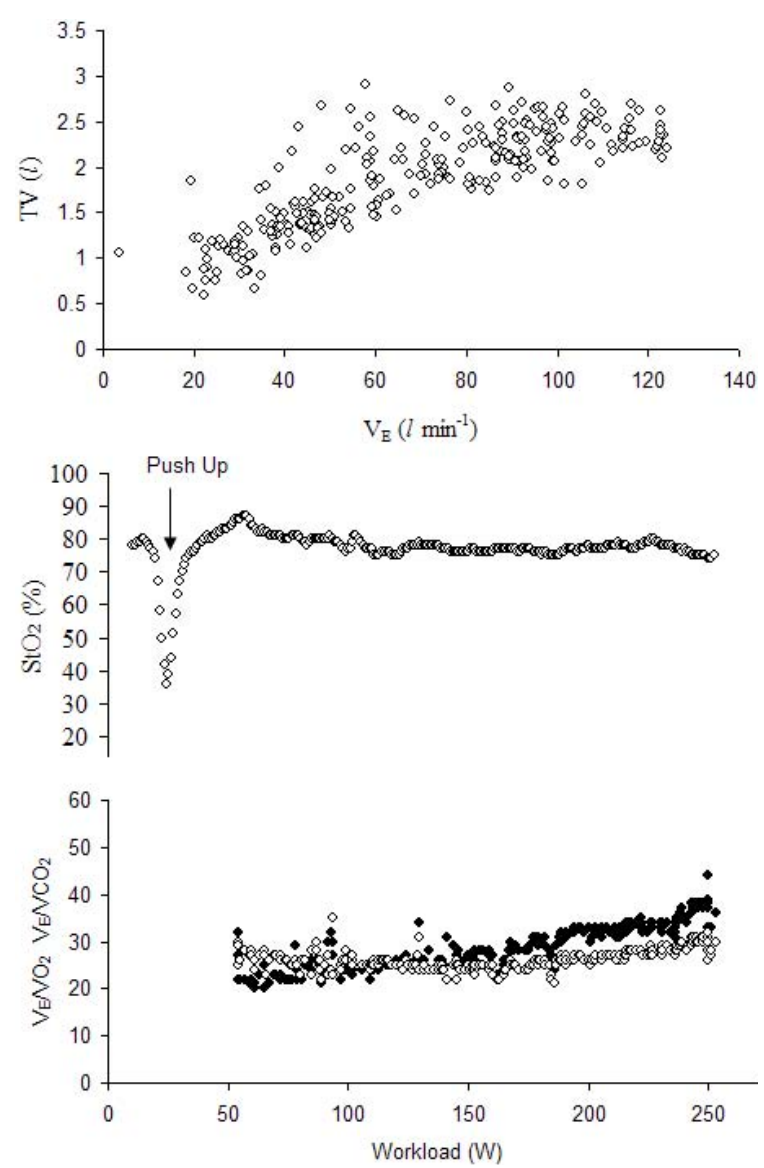

Fig. 1. Representative subject responses. Tidal volume (TV), serratus anterior (SA) tissue saturation $\left(\mathrm{StO}_{2}\right)$, ventilatory equivalents of $\dot{\mathrm{V}} \mathrm{O}_{2}$ (closed symbols), and $\dot{\mathrm{V}} \mathrm{CO}_{2}$ (open symbols) during manual muscle tests (5-10 push-ups) and subsequent graded exercise to volitional exhaustion. trometer with a data acquisition rate of $0.3 \mathrm{~Hz}$ (In-Spectra Model 325, Hutchinson Technology Inc., Hutchinson, $\mathrm{MN})$. The changes in muscle oxygenation, indicative of $\mathrm{O}_{2}$ consumption and availability [24], were determined from differential absorption of near infrared light at 680 and $800 \mathrm{~nm}$. These changes reflect the differential light absorption of predominantly oxy- and deoxyhemoglobin [25-27] and correlate strongly with local perfusion [20]. The infrared probe was placed at the sixth intercostal space, at the anterior axillary line as described elsewhere $[12,16]$. Probes with 12, 25, and $35 \mathrm{~mm}$ spacing between the light source and photodectector were used. The near infrared light penetrates into the tissues at a depth of roughly half the distance between the light source and the photodetector [28, 29]. The probe selection was customized per subject depending on the measured skinfold thickness over the SA by using a Lange Caliper (Beta Technology Inc., Cambridge, MD, USA). The subject was then fitted with the probe shield, which was affixed to the skin with adhesive tape along with the probe. A push-up test was used to ensure the ability to measure tissue deoxygenation in the SA resulting from muscular effort (Fig. 1). The subjects were excluded from the study if the investigator was unable to identify muscle deoxygenation with the push-up test by using any of the three near infrared probes. The $\mathrm{StO}_{2}$ data points were generated from 30-s means during the exercise test. The data were visually inspected to identify common values aligned with EMG data in relation to the $\% \dot{\mathrm{V}} \mathrm{O}_{2 \max }$ of the subjects.

Statistical analyses. A one-way repeated measures analysis of variance (ANOVA) was used to identify differences across the time periods during the exercise test for the $\mathrm{StO}_{2}$ and EMG of the SA. Significance was determined at $P<0.05$. All data were analyzed with the Statistical Package for the Social Sciences (SPSS, v13.0, SPSS Inc., Chicago, IL, USA). The data are presented as means $\pm \mathrm{SE}$.

\section{RESULTS}

The EMG and $\mathrm{StO}_{2}$ measurements during the graded exercise test allowed for data to be grouped at 7 intervals

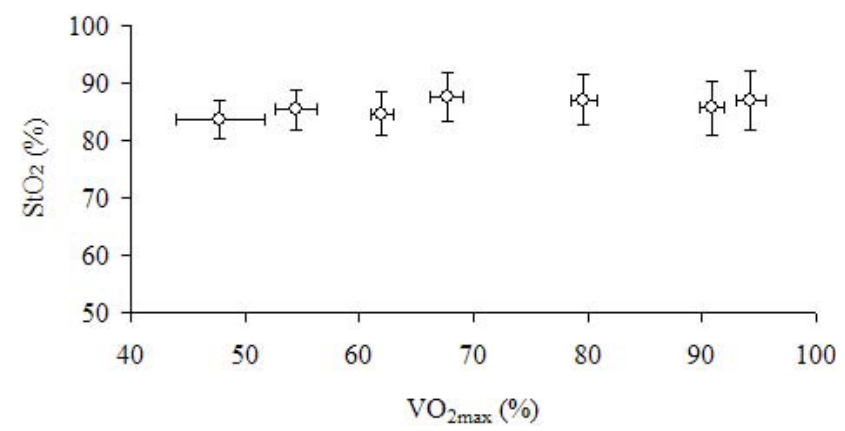

Fig. 2. $\mathrm{StO}_{2}$ data (means $\pm \mathrm{SE}$ ) of serratus anterior (SA) during graded exercise. 


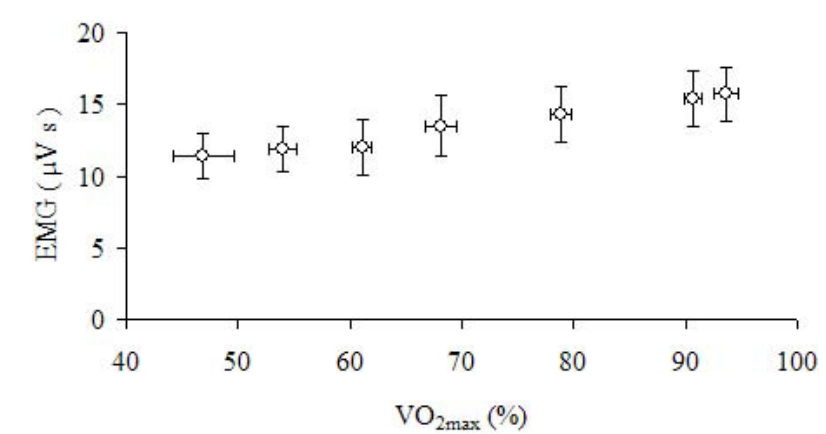

Fig. 3. EMG data (means $\pm \mathrm{SE}$ ) of serratus anterior $(S A)$ during graded exercise.

representing a range of $\sim 45 \%-95 \% \dot{\mathrm{V}} \mathrm{O}_{2 \max }$. An examination of Mauchly's W revealed a severe violation of sphericity in both $\mathrm{StO}_{2}$ and EMG data. Greenhouse-Geissercorrected $\mathrm{F}$ values were used for both variables. The results of a one-way repeated measures ANOVA revealed no significant differences during exercise for either $\mathrm{StO}_{2}$ $\left(n=6, \mathrm{~F}[1.532,7.661]=0.895, P>0.05, \eta^{2}=0.15\right)$ (Fig. 2) or $\mathrm{EMG}\left(n=9, \mathrm{~F}[1.594,12.75]=3.067, P>0.05, \eta^{2}=\right.$ 0.27) (Fig. 3). Because of a failure of the infrared probe, the NIRS data of 3 subjects were not successfully recorded and were excluded from analysis. No phasic EMG activity was identified in any of the 9 subjects (Fig. 4). $\mathrm{V}_{\mathrm{T}}$ and peak values for $\dot{\mathrm{VO}}_{2}, \dot{\mathrm{V}}_{\mathrm{E}}$, and TV are presented with subject characteristics in Table 1.

\section{DISCUSSION}

This investigation utilized EMG and NIRS to determine the recruitment and oxygenation of the SA during graded upright cycling. Muscular effort not related to ventilation was controlled by the positioning of the subjects' arms at the abdomen. It is noteworthy that the experimental posture was not an intended suppression of muscular effort at the SA; it simply provided control for the motor unit recruitment resulting from pushing-forward flexion during cycle ergometry. The primary findings of this investigation were no changes in $\mathrm{StO}_{2}$ or EMG during graded upright cycling. No clear phasic activation of the SA in any subject's EMG data and no changes in $\mathrm{StO}_{2}$ during exercise to volitional exhaustion indicated little muscular effort of the SA.

Electromyographic data represent minimal activity $(\sim 15 \mu \mathrm{V} s)$ and nonsignificant changes on the scale of $\sim 4$ $\mu \mathrm{V}$ s (Figs. 3 and 4 ). Using the same $2.5 \mathrm{~s}$ period, the EMG during push-up testing equaled $53.2 \pm 7.14 \mu \mathrm{V} \mathrm{s}$, as compared with $\sim 16 \mu \mathrm{V}$ s measured during the exercise test at $\sim 94 \% \dot{\mathrm{VO}_{2 \max }}$ (Fig. 4). Although this method is not an optimal approach to analyzing a push-up, it does provide a relative comparison of the muscular effort of the SA during these two conditions. Previous investigations have successfully identified phasic activity in the SA during quiet, and more readily during forced inspiration and

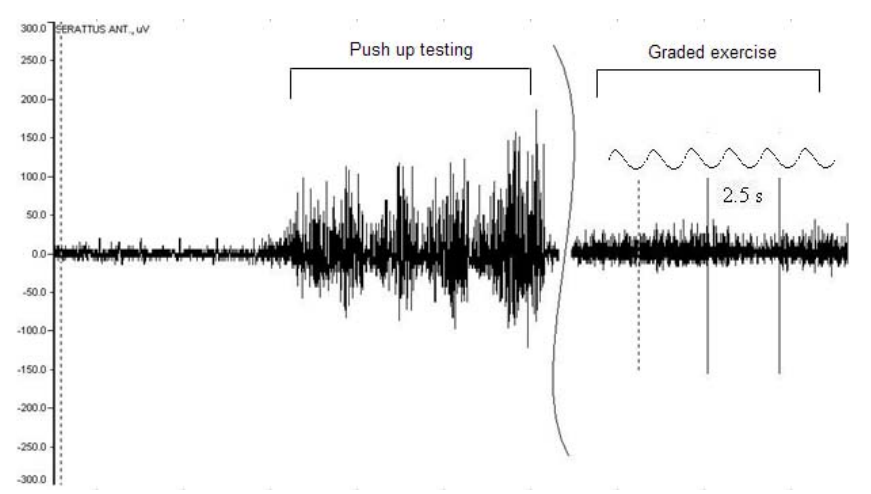

Fig. 4. Raw EMG tracings and respiratory cycle from a representative subject $\left(\dot{\mathrm{V}} \mathrm{O}_{2 \max }=3.204 / \mathrm{min}^{-1} ; \dot{\mathrm{V}}_{\text {Epeak }}=117.3 / \mathrm{min}^{-1}\right.$; $\left.\mathrm{TV}_{\text {peak }}=2.509 \mathrm{I}\right)$ during push-up testing and graded exercise. The sine wave represents a respiratory cycle of 49 breaths per min at $\sim 90 \% \dot{V}_{2 \max }$. The vertical lines represent a $2.5-\mathrm{s}$ period during the graded exercise test taken at $\sim 90 \% \dot{\mathrm{V}}_{2 \text { max }}$.

expiration [4-6]. The findings of the current investigation do not intend to confirm or refute these results; to our knowledge, there exists no other experimental EMG data for the SA during the expected ventilation changes during graded exercise (Fig. 1). The SA is an inherently difficult muscle to study as activity from ventilation is cited in modern texts as little more than a source of artifact. Furthermore, EMG data collection during exercise may suffer from artifact associated with skin stretching, conduction changes because of sweating, and movement artifact in the electrode leads [22]. Although a lack of sensitivity cannot be ruled out to explain an absence of phasic action, EMG activity was consistently minimal, indicating negligible motor unit recruitment.

Because tissue oxygenation represents the balance between $\mathrm{O}_{2}$ consumption and availability [24] and the SA exhibited no fall in oxygenation, the data indicated little muscular effort. It has been previously reported that healthy individuals exhibit from minimal to no tissue deoxygenation of the SA at peak exercise, even while grasping the handlebars [16], yet patients with congestive heart failure have consistently presented with early and progressive deoxygenation of the SA, often termed as "respiratory muscle deoxygenation," and it has been postulated as an indication of diaphragmatic deoxygenation and possible cause of dyspnea in cardiac patients $[12,16$, 17]. Healthy children and adults have also been observed to present this phenomenon [13-15], but many questions remain unresolved as to the specific action of the SA and the ability to make inferences to other respiratory muscles and their oxygenation state during exercise. The findings of the present investigation indicated the recruitment of the SA during graded exercise as minimal and suggested that the findings of previous investigations utilizing cycle ergometry may have been confounded by the subjects grasping the handlebars. A forward flexion of the arms and/or a pushing motion observed during cycle ergometry 
may have resulted in an increase in muscular effort resulting from scapular stabilization, rather than ventilation alone. These actions are described as manual muscle tests for the SA [23] and must be accounted for when examining the ventilatory action of the SA. Further, the fall in oxygenation has also been shown in nonexercising tissue $[18$, 19], suggesting that perfusion and oxygenation changes may be present without muscular effort, further complicating the inferences to respiratory musculature based on the SA. Although blood flow and perfusion were not quantified in the current investigation, future research on the accessory respiratory muscles may need to account for the redistribution of blood flow to the chest wall, or the "steal effect" between exercising skeletal muscle and respiratory musculature, as previously reported with increasing respiratory work $[30,31]$.

Although the recruitment of the SA has been postulated to aid in ventilation in various postures and disease states, it is concluded that the SA shows little muscular effort in healthy subjects during maximally graded upright cycling. Additional research is needed to conclude the pertinence of utilizing $\mathrm{StO}_{2}$ of the $\mathrm{SA}$ as an analog for respiratory muscle oxygenation.

\section{REFERENCES}

1. Catton WT, Gray JE. Electromyographic study of the action of the serratus anterior muscle in respiration. J Anat. 1951;85:412.

2. Gronbaek P, Skouby AP. The activity pattern of the diaphragm and some muscles of the neck and trunk in chronic asthmatics and normal controls. Acta Med Scand. 1960;168:413-25.

3. Campbell EJM. Accessory muscles. In: Campbell EJM, Agostoni E, Davis NJ, eds. The Respiratory muscles: mechanics and neural control. W.B. Philadelphia: Saunders; 1970. p. 187.

4. Reid DC, Bowden J, Lynne-Davies P. Role of selected muscles of respiration as influenced by posture and tidal volume. Chest. 1976;70:636-40.

5. Machado de Sousa O, Costacurta L. Electromyographic study of the m. serratus anterior during respiration. Electromyogr Clin Neurophysiol. 1984;24:547-59.

6. Cerqueira EP, Garbellini D. Electromyographic study of the pectoralis major, serratus anterior and external oblique muscles during respiratory activity in humans. Electromyogr Clin Neurophysiol. 1999;39:131-7.

7. Martini FH, Timmons MJ, Tallitsch RB. Human anatomy. Upper Saddle River: Prentice Hall; 2004.

8. Duchenne GB. Physiology of Motion: Demonstrate by means of electrical stimulation and clinical observation and applied to the study of paralysis and deformities, 1867. Translated by E.B. Kaplan. Philadelphia: W.B. Saunders Company; 1959

9. Jefferson NC, Ogawa T, Syleos C, Zambetoglou A, Necheles H. Restoration of respiration by nerve anastomosis. Am J Physiol. 1960;198:931-3.

10. Basmajian JV, DeLuca CJ. Muscles alive: Their functions revealed by electromyography. 5th Edition. Baltimore: Wiliams \& Wilkins; 1985.

11. Boushel R, Langberg H, Olesen J, Gonzales-Alonzo J, Bulow J, Kjaer M. Monitoring tissue oxygen availability with near infrared spectroscopy (NIRS) in health and disease. Scand J Med Sci Sports. 2001;11:213-22.

12. Terakado S, Takeuchi T, Takeshi M, Sato H, Nishioka N, Fujieda Y, Kobayashi R, Ibukiyama C. Early occurrence of respiratory muscle deoxygenation assessed by near-infrared spectroscopy during leg exercise in patients with chronic heart failure. Jpn Circ J. 1999;63:97-103.

13. Moalla W, Dupont G, Berthoin S, Ahmaidi S. Respiratory muscle deoxygenation and ventilatory threshold assessments using near infrared spectroscopy in children. Int J Sports Med. 2005;26:576-82.

14. Legrand R, Prieur F, Marles A, Nourry C, Lazzari S, Blondel N, Mucci P. Respiratory muscle oxygenation kinetics: Relationships with breathing pattern during exercise. Int J Sports Med. 2007;28:91-9.

15. Legrand R, Marles A, Prieur F, Lazzari S, Blondel N, Mucci P. Related trends in locomotor and respiratory muscle oxygenation during exercise. Med Sci Sports Exerc. 2007:39:91-100

16. Mancini DM, Ferraro N, Nazzaro D, Chance B, Wilson JR. Respiratory muscle deoxygenation during exercise in patients with heart failure demonstrated with near-infrared spectroscopy. J Am Coll Cardiol. 1991;18:492-8.

17. Mancini DM, Henson D, LaManca J, Levine S. Respiratory muscle function and dyspnea in patients with chronic congestive heart failure. Circulation. 1992;86:909-18.

18. Ogata H, Reyihan A, Yano T. Kinetics of oxygenation in active forearm muscle during ramp leg exercise. J Physiol Anthropol Appl Human Sci. 2004;23:7-17.

19. Ogata H, Arimitsu T, Matsuura R, Yunoki T, Horiuchi M, Yano T. Relationship between oxygenation in inactive biceps brachii muscle and hyperventilation during leg cycling. Physiol Res. 2006 [E published ahead of print, pre-press]

20. Wang L, Yoshikawa T, Hara T, Nakao H, Suzuki T, Fujimoto S. Which common NIRS variable reflects muscle estimated lactate threshold most closely? Appl Physiol Nutr Metab. 2006;31:612-20.

21. Beaver WL, Wasserman K, Whipp BJ. A new method for detecting anaerobic threshold by gas exchange. J Appl Physiol. 1986;60:2020-7.

22. Cram JR, Kasman GS, with Holtz J. Introduction to surface electromyography. Gaithersburg: Aspen Publishers Inc.; 1998.

23. Rasch PJ, Burke RK. Kinesiology and applied anatomy. Philadelphia: Lea \& Febiger; 1978.

24. Miura $\mathrm{H}$, Araki $\mathrm{H}$, Matoba $\mathrm{H}$, Kitagawa K. Relation among oxygenation, myoelectric activity, and lactic acid accumulation in vastus lateralis muscle during exercise with constant work rate. Int J Sports Med. 2000;21:180-4.

25. Seiyama A, Hazeki O, Tamura M. Nonivasive quantitative analysis of blood oxygenation in rat skeletal muscle. J Biochem. 1988;103:419-24.

26. Wilson JR, Mancini DM, McCully K, Ferraro N, Lanoce V, Chance B. Noninvasive detection of skeletal muscle underperfusion with near-infrared spectroscopy in patients with heart failure. Circulation. 1989;80:1668-74.

27. Mancini D, Bolinger L, Li H, Kendrick K, Chance B, Wilson J. Validation of nearinfrared spectroscopy in humans. J Appl Physiol. 1994;77:2740-7.

28. Patterson $M$, Chance $B$, Wilson $B$. Time resolved reflectance and transmittance for non-invasive measurement of tissue optical properties. Appl Optics. 1989;28:2331-6.

29. McCully K, Hamaoka T. Near infrared spectroscopy: what can it tell us about oxygen saturation in skeletal muscle? Exerc Sport Sci Rev. 2000;28:123-7.

30. Harms CA, Babcock MA, McClaran SR, Pegelow DF, Nickele GA, Nelson WB, Dempsey JA. Respiratory muscle work compromises leg blood flow during maximal exercise. J Appl Physiol. 1997;82:1573-85.

31. Harms CA. Effect of skeletal muscle demand on cardiovascular function. Med Sci Sports Exerc. 2000;32:94-9. 